\title{
Managerial Perceptions of the Impact of HRIS on Organizational Efficiency
}

\author{
Nikhal Aswanth Kumar, *Sanjana Brijball Parumasur \\ University of KwaZulu-Natal (Westville Campus) Durban, South Africa \\ *brijballs@ukzn.ac.za
}

\begin{abstract}
This study evaluates the impact of the HRIS system on HR functions, time management, cost management, managerial satisfaction and organizational efficiency. A sample of 101 managers was drawn from a Municipality in South Africa using cluster sampling. Data was collected using a selfdeveloped, closed-ended questionnaire comprising of 28 items, the psychometric properties (validity, reliability) of which was statistically assessed using Factor Analysis and Cronbach's Coefficient Alpha respectively. Data was analyzed using descriptive and inferential statistics. The results indicate that managers have a fairly positive view of the impact of the HRIS on organizational effectiveness with the greatest degree of confidence being placed on the impact of HRIS on time management and on HR functions. The results confirm that a well implemented and managed HRIS enables readily available information to be translated into more information sharing, greater knowledge transfer and management. Consequently, the HRIS has the potential to enhance the speed and quality of decision making and the realisation of the HR strategy, thereby enhancing organizational effectiveness.
\end{abstract}

Keywords: Human Resource Information System (HRIS), human resource functions, time management, cost management, managerial satisfaction, organizational efficiency

\section{Introduction}

An organization's human resources are its greatest asset and the effective management of its human capital is a fundament source of competitive advantage. Organizations worldwide have begun to realize the importance of personnel in driving the strategic focus and realising the goals of the business and have concurrently invested in technology and, in particular, Human Resource Information Systems (HRIS) to recruit support and manage its HR. Hence, over the past decade, the use of HRIS in the private as well as the public sector has increased. A United States of America survey illustrated that $70 \%$ of large firms use HRIS, $80 \%$ conduct online recruiting, $67 \%$ post job openings online, and $40 \%$ use web-based portals as a means of communicating company policies (Grobler, Warnich, Carrell, Elbert \& Hatflied, 2006). Whilst HRIS is successfully utilised in China, Wei and Feng (2013) believe that there are many problems being experienced in the application of HRIS in Chinese SMEs including information content, information management and system evaluation. In their survey on UK companies, Kinnie and Arthurs (1996) found that the most frequent uses of HRIS were in operational areas of employee records (72\%) followed by payroll (66\%) and pensions (57\%). Likewise, Teo, Soon and Fedric (2001) found that HRIS was predominantly used for employee record keeping (96.8\%) and payroll (90.5\%). In Hong Kong companies, HRIS was used the most for providing general information $(86.4 \%)$ and payroll services (84.7\%). In India, service organizations apply HRIS in performance and reward management more than manufacturing companies (Kundu \& Kadian, 2012). Evidently, information technology is having a drastic impact globally on the function of human resource management. However, an increase in the use of HRIS does not imply successful implementation of the HRIS in contributing to the strategic direction of the organization and the effective realization of corporate goals.

Therefore, this research examines the effectiveness of HRIS in a Municipality in South Africa with a population of approximately four million people, a number of popular attractions and Africa's premier port. Effective revenue collection and expenditure, excellent financial management and reporting, and viable and sustainable budgeting are imperative for its functions, service delivery and growth. The Municipality has 23000 employees and the Human Resources Department within the Municipality is responsible for managing these employees. This includes employees from eight sectors, namely, Office of the City Manager, Finance, Programme Management, Corporate and Human Resources, Human Settlements and Infrastructure, Community and Emergence Services and, Economic Development and Planning. Evidently, managing 23000 employees in these large sectors can become a complex task. This emphasizes the need for the implementation of an effective, integrated HRIS to manage employees' concerns, salaries, details, benefits, leave administration and other functions in a timely and organised 
manner. Therefore, this research examines managerial perceptions of the role that HRIS is playing in assisting the HR department of the Municipality in improving HR operations and being efficient and effective. In particular, the study examines managerial satisfaction with the HRIS system and its perceived impact on time management, cost management, HR functions and overall organizational effectiveness.

This study is particularly important because the Municipality previously used the HR system called UniQue Payroll system but changed to DynamiQue ResourceLink (DRL) which is supplied by Business Connexion (Pty) Ltd. While the UniQue Payroll and Human Resource System has served the Municipality well during its transition phase, the Municipality aimed to replace the system with a fully integrated, online, shared human resource management information system which will accommodate all the foreseen HR and management information needs of the Municipality (Appanna, 2008), which was better served by the DynamiQue Resource Link system. Another main driving force for the transition from UniQue to DRL was due to a paperless environment initiative by the Municipality. Given that DRL is an online system, this fitted into the organisation's requirements. The differences between UniQue Payroll and DRL are summarized in Table 1.

Table 1: Differences between UniQue and DRL

\begin{tabular}{ll}
\hline UniQue Payroll System & DynamiQue Resource Link \\
\hline $\begin{array}{l}\text { Manual calculations are done when an employee } \\
\text { enters and leaves the Municipality; therefore, it }\end{array}$ & $\begin{array}{l}\text { DRL automates this process, which results in it } \\
\text { being more flexible and accurate data capturing and } \\
\text { takes time in terms of workflow processes which } \\
\text { allows for shorter response time and information is } \\
\text { results in a longer response time for queries. }\end{array}$ \\
$\begin{array}{l}\text { No self service facilities; all queries have to go to } \\
\text { the pay section to be resolved. }\end{array}$ & $\begin{array}{l}\text { DRL offers the self service facility which is an } \\
\text { advantage to every employee of the Municipality. }\end{array}$ \\
$\begin{array}{l}\text { Currently has Org Plus which does organograms } \\
\text { that maintain staff establishment, staff }\end{array}$ & $\begin{array}{l}\text { DRL is an integrated system and no department has } \\
\text { movements, vacancies and so on. }\end{array}$ \\
$\begin{array}{l}\text { There is duplication in terms of capturing } \\
\text { employee information, because it is done } \\
\text { manually. }\end{array}$ & $\begin{array}{l}\text { In DRL, duplication is prevented in that all } \\
\text { Back pay takes a long time to process as it involves automated. } \\
\text { manual capturing. }\end{array}$ \\
\hline
\end{tabular}

Govender, Pillay \& Silelidis (2010). Human Resources Unit Presents: A new Software Package. [Power Point Slides]. Presented at: HR Shared Services Meeting. p. 1.

\section{Definition and Nature of HRIS}

There are a number of definitions provided for HRIS. Kavanagh and Thite (2009) define a Human Resource Information System (HRIS) as a system used to acquire, store, manipulate, analyze, retrieve, and distribute resources. A HRIS is not simply computer hardware and associated HR-related software but it also includes people, forms, policies and procedures, and data. However, Grobler et al. (2006, p. 40) define HRIS as "the primary transaction processor, editor, record-keeper, and functional application system which lies at the heart of all computerised Human Resources (HR) work. HRIS maintains employee, organizational and HR plan data sufficient to support mostly all HR functions". As technology has advanced over the past decade, so too has the need to replace the traditional method of recording employee data on paper. In conjunction with technology, the HR field has certainly changed dynamically over the years in playing a more strategic role in organizations. Powered by the capabilities of information systems as well as the internet, today almost all HR functions are being computerised (Kavanagh \& Thite, 2009). HRIS is usually part of a company's larger management information system (MIS) which will include other functions such as accounting, finance, marketing and production (Carrell, Elbert, Hatfield, Grobler, Marx \& van der Schyf, 1999).

Importance of HRIS: It has become clear to organizations that the traditional paper method of keeping records is not efficient anymore. Human resource is an extremely valuable resource and is the ultimate source of core competitive advantage (Wei \& Feng, 2013). Despite this, there was clearly an incongruence 
between the way in which HR practitioners were expending their time and effort and what can truly make a difference to the bottom line and the success of the organization (NMA Technologies, 2008). Traditionally, HR practitioners were exerting the most significant proportion of time and effort at the administrative level; followed by the operational level and lastly, the strategy level yet the converse will produce an HR value add. HRIS has the potential to transform HR and enable it to contribute value add to the organization by supporting that the least amount of time is spent at the administrative level and that the time saved is dedicated to the strategic level. Furthermore, taking cognizance of the greater involvement HR is playing in the strategic planning process of companies, the need for HRIS is vital. A strategic HRIS provides important information about human resources' needs and capabilities; this information is imperative for management to establish the organizational mission and set and implement goals and objectives (Chauhan, Sharma \& Tyagi, 2011). Apart from its success, the survival of an organization depends on how effectively the right information is collected and used for taking the right decision in the right context (Nawaz, 2012).

According to Hendrikson (2003, p. 382), "over the past two decades, firms have increasingly relied on the HR function to provide management solutions that increase the effectiveness of human capital". HRIS systems have evolved into complex tools designed to manage a rich variety of information about the firm's human capital as well as to provide analytical tools to assist in decision making about the management of those assets. A well designed HRIS can serve as the main management tool in the alignment or integration of the human resources department goals with the goals of long-term corporate strategic planning (Carrell et al., 1999). HR data needs to be presented to managers to aid decision making in the organization. This overall concept is known as Decision Support System (DSS) (Carrell et al., 1999). With the increasing importance of HR issues as critical factors in strategic planning and decision making, the ability of the HRIS to quantify, analyze and model change becomes extremely important (Carrell et al., 1999). Effective HRIS capabilities can provide a company with competitive and strategic advantage while going through a change process.

With the debut of large, competitive, dynamic and multinational industries, companies are now considering global HRIS implementation projects. There are numerous global HR systems available that can support the basic HR processes from employee recruitment to termination as well as benefits administration, total compensation, absence management, time tracking, payroll and talent management associated with learning, performance, career and succession planning modules (Carneiro, 2011). Certainly global HRIS implementation projects face the challenges of differences and uniqueness in different countries and regions such as cultural differences and language barriers. However, a global HRIS enables more accurate planning and more transparent decisions. Global HRIS transcends beyond the ability to analyze and use employee data as the system supports geographically diverse operations to share ideas and innovations (Miller, 2004) and to create an ethos of cultural cohesion and closeness for employees (Insight Consulting Partners, 2004). Whether local or global, HRIS has the potential to bring about improved planning and program development, decreased administrative and HR costs, accuracy of information and enhanced communication at all levels, thereby adding competitive value to the organization. Although HRIS offers a wide variety of advantages, a range of issues arising from the new system adopted in the target Municipality has an influence on managerial satisfaction with the system, time management, cost management, HR functions and organizational effectiveness. This study sets out to explore the impact of HRIS on each of these variables:

Managerial satisfaction: In the Municipality concerned, as issues were discovered pertaining to the old HRIS, managerial satisfaction with the system declined and hence, a new system was sought after. An effective HRIS ultimately aims to make the HR process more efficient and faster thus, bringing about managerial satisfaction. However, if not properly implemented or effectively utilized, the HRIS can fail to bring about managerial satisfaction. Fundamental to a successful implementation of a HRIS is support from executive management and formalized cross-functional support teams (Insight Consulting Partners, 2012). Managerial satisfaction with the HRIS is enhanced when the system's advantages for management are realized, namely, the increase of overall decision-making efficiency, cost reduction and improved control of budget, business transparency, a clear business vision and a clear insight into the process of recruitment, selection and termination of employees at the aggregate level (Dorel \& Bradic-Martinovic, 2011). Johnson and Gueutal (2012) caution that although HR staff and line employees will have access to volumes of data to support decision-making, the latter does not improve measurably though time-todecision is reduced. Satisfaction with the HRIS is also influenced by system quality; information quality and perceived ease of use (Bal, Bozkurt \& Ertemsir, 2012). 
Time management: HR personnel used to be overburdened with the administrative task of keeping records on staff using manual spreadsheets which were difficult and time consuming to capture and maintain. Hence, HR information systems were implemented to reduce the total time that employees spend on routine administrative functions. This enables HR staff to focus on more strategic tasks and become a strategic provider or professional consultant to the rest of the organization and business (Becker, Huselid \& Ulrich, 2001; Lawler \& Mohrman, 2003; Lengnick-Hall \& Moritz, 2003; Lawler, Levenson \& Boudreau, 2004; Sheehan, Holland \& De Cieri, 2006; Shiri, 2012). However, researchers have found that although upgraded HRIS are being used to automate and devolve administrative tasks traditionally undertaken by the HR function, the system is not currently being used in ways that contribute to the strategic direction of the organization (Dery, Grant and Wiblen, 2009; Sadiq, Khan, Ikhlaq \& Mujtaba, 2012). Dery et al. (2009) add that the extent to which the HRIS acts as an enabler to increased strategic focus for HR depends on organizational attention, understanding of the technological responses to HRM complexity and the success of change management to facilitate user acceptance. An online streaming HRIS can process huge amounts of data with accuracy, thereby preventing employees from having to do such activities manually. Furthermore, many HRI Systems incorporate self-service options whereby employees can access and update their own personal records, change or enrol in employee benefit plans and respond timeously to employment opportunities in other areas thereby saving the employee time and the HR personnel effort in engaging in routine activities. When employees can log in and find information online it results in fewer calls to HR personnel, thereby even enabling the organization to maintain a lower HR to employee ratio. The added advantage is that HRIS can provide a single, safe repository for confidential HR information to be available 24/7 from any place with access to the internet. It therefore, has the benefit of reducing redundancy within the organization due to its centrality of information and easy accessibility. It also enhances the ability to create reports and analyze information speedily and accurately, thereby making the workforce easier to manage (Lucerna, 2013). Johnson and Gueutal (2012) believe that providing employees with access to their information increases the transparency of HR processes, helps them to better understand the role of HR in the organization, and makes them feel they have control over their information which can lead to an enhanced sense of fairness and job satisfaction.

Cost management: Whilst it could be a large investment into acquiring a HRIS, many organizations view it as a long term investment. Costs are decreased when a HRIS is implemented due to less paper been used, less space being taken up, and due to the system being faster and more accurate. Therefore, the excessive costs of a HRIS can be justified and an organization will begin to experience its return on investment. For example, IBM has a paperless online plan for all its employees, which has not only saved the company $\$ 1.2$ million a year in terms of printing and mailing costs, but the employees enjoy working with the online plan (Brown, 2008). Being a computerized system, a HRIS should provide the capability to more effectively plan, control and manage HR costs such as labour and recruitment costs (Khera \& Gulati, 2012).

Impact on various HR functions: HRIS has a spill over effect to almost all HR functions such as application tracking in recruitment and selection, personnel information and identification, salary planning, absenteeism analysis, turnover analysis, work scheduling, training and development, performance management, succession planning, compensation, conflict resolution and manpower planning. When the system is not performing well or a glitch occurs, all the relevant HR divisions are affected and will suffer as a result. Thus, an organization has to be extremely cautious when choosing a HRIS to ensure that it positively impacts on various other HR functions. In most situations, a HRIS leads to greater efficiency with regards to making decisions in HR. The HRIS enables the organization to achieve improved efficiency and quality in HR decision-making and improve employee and managerial productivity and effectiveness (Dresser \& Associates, 2013). Khera and Gulati (2012) maintain that while HRIS helps in the strategic activities of HR managers, it is dominant in identifying occupied and unoccupied positions in an organization very effectively and accurately and therefore, assists in planning the organization's human resources both qualitatively and quantitatively. The latter benefit was also emphasized by Dessler (2005). Similarly, Shiri (2012) found that HRIS produces more effective and faster outcomes, has brought about an improvement in the overall HR functions and has assisted in aligning HR practices with the organizational strategy, identifying improvement areas and keeping ahead of current practices thereby enhancing the efficiency of the HR function.

Organizational effectiveness: A HRIS brings about organizational effectiveness in the sense that the HR department is more efficient and employees and management can access any of their records online 
whenever they need too. It removes the burden of HR to carry out mundane requests from employees thus, giving HR staff more time to spend on strategic tasks. Modern HRISs have such extensive features that employees have everything they need at their fingertips. Lengnick-Hall \& Moritz (2003) believe that HRIS will bring about informational efficiencies and time and cost savings that will enable HR departments to turn their attention to providing better and accurate analysis of current data upon which strategic business decisions may be made. Similarly, Shiri (2012) found that HRIS provides HR professional with opportunities to enhance their contribution to the strategic direction of the firm. However, Beadles II, Lowery \& Johns (2005) found that HRIS has not yet accomplished this or reached its full potential in the HR environment. In their study, they found that whilst directors overall are satisfied with the system, they have not yet realized the benefits beyond its effect on information and information sharing as the full capabilities of the system were being underutilized. Kumar (2012) emphasizes that whilst HRIS is an important tool for HRM as it has the potential to provide better information for decision-making; its effectiveness depends on the challenges of its implementation and its effective integration within the organization. Evaluating the HRIS in the Municipality based on the aforementioned dimensions reflects the value of the HRIS in both operational and strategic functions.

Problem Statement: To what extent does the HRIS system of the Municipality impact on HR functions, time management, cost management, managerial satisfaction and organizational efficiency?

Objectives of Study: This study aims:

- To assess the perceived influence of HRIS of the Municipality on organizational efficiency (impact on areas of HR, time management, cost management, managerial satisfaction with the system).

- To assess the impact of the biographical variables (age, gender, length of service, race, highest educational level and department) on the perception of managers regarding the influence of HRIS on organizational efficiency (impact on areas of HR, time management, cost management, managerial satisfaction with the system) respectively.

\section{Methodology}

Research approach: The research methodology has been designed to assess the perceived influence of HRIS of the Municipality on organizational efficiency (impact on areas of HR, time management, cost management, managerial satisfaction with the system).

Respondents: The population comprised of managers of the Municipality from the eight different departments, namely, Office of the City Manager, Finance, Programme Management, Corporate and Human Resources, Governance, Human Settlements and Infrastructure, Community and Emergency Services and, Economic Development and Planning. Managers were chosen as the population due to their increased roles and responsibility, span of control and their ability to execute a wide range of business related decisions. Managers in the Municipality are graded according to the Municipality's grading system. The scale begins at 1, which represents the lowest job level and advances until 25, which represents the most senior position(s) in the Municipality. Managers that were used in this study are Level (Task) 14 and above.

The total number of managers from Level 14 and above from all eight departments is 130. According to Sekaran and Bougie (2010), the corresponding minimum sample size for a population of 130 is 97 , thereby confirming the adequacy of the sample of 101 managers for the study. Cluster sampling will be used due to the concentration of managers in the eight different departments. Using cluster sampling will also reflect how the different departments view their HRIS respectively. In terms of the composition, $41.6 \%$ of the managers are $41-50$ years of age, $23.8 \%$ are $31-40$ years, $18.8 \%$ are $21-30$ years and the remaining $15.8 \%$ are over 50 years old. In addition, $58.4 \%$ of the managers are females whilst $41.6 \%$ are males. The majority of the respondents are Indian (42.6\%), followed by Black (40.5\%), then Whites $(11.9 \%)$ and lastly, Coloureds (5\%). In terms of tenure, the majority of the managers are working in the organization for $0-5$ years (47.5), $22.8 \%$ served for a term of 16 years and above, $16.8 \%$ for $6-10$ years and $12.9 \%$ for $11-15$ years. The majority of the sample was from Corporate and Human Resources $(64.4 \%)$ whilst the remaining percentage almost equally represented all other clusters/departments. The adequacy of the sample was further determined using the Kaiser-Meyer-Olkin Measure of Sampling Adequacy (0.838; approx. $\left.\chi^{2}=1460.562\right)$ and the Bartlett's Test of Spherecity $(378, p=0.000)$, which respectively indicated suitability and significance. The results indicate that the normality and homoscedasticity preconditions are satisfied. 
Measuring Instrument: Data was collected using a self-developed questionnaire consisting of Section A (biographical information relating to age, gender, race, tenure and cluster/department) and Section B which included items relating to the perceived impact of HRIS in the Municipality. The biographical data in Section A was collected using a nominal scale with pre-coded option categories and the items in Sections B were measured using a 5-point Likert scale ranging from strongly disagree (1), disagree (2), neither agree/not disagree (3), agree (4) to strongly agree (5). Section B of the questionnaire was formulated on the basis of identifying recurring themes that surfaced during the literature review and the 28 items included in the questionnaire related directly to the constructs being measured ( 7 items relate to the impact of HRIS on the HR functions, 5 items assess the impact of HRIS on time management, 5 items relate to the impact of HRIS on cost management, 6 items assess managerial satisfaction with the HRIS, and 5 items relate to the impact of HRIS on organizational efficiency). This ensured face and content validity. Furthermore, in-house pretesting was adopted to assess the suitability of the instrument. Pilot testing was also carried out using 6 managers, selected using the same procedures and protocols adopted for the larger sample. The feedback from the pilot testing confirmed that the questionnaire was appropriate in terms of relevance and construction.

Statistical measures of the questionnaire: The validity of the questionnaire was assessed using Factor Analysis. A principal component analysis was used to extract initial factors and an iterated principal factor analysis was performed using SPSS with an Orthogonal Varimax Rotation. Only items with loadings $>0.5$ were considered to be significant and when items were significantly loaded on more than one factor only that with the highest value was selected. In terms of the sub-dimensions of HRIS being assessed (Section B), 5 factors with latent roots greater than unity were extracted from the factor loading matrix. Factor 1 relates to managerial satisfaction with the HRIS and accounts for $17.4 \%$ of the total variance, Factor 2 pertains to the impact of HRIS on cost management and accounts for $13.8 \%$ of the total variance and Factor 3 relates to the impact of HRIS on time management and accounts for $11.7 \%$ of the total variance, Factor 4 relates to the impact of HRIS on the HR functions and accounts for $8.9 \%$ of the total variance and Factor 5 pertains to the impact of HRIS on organizational efficiency and accounts for $7.1 \%$ of the total variance in determining the impact of HRIS in the Municipality. The reliability of Section B of the questionnaire relating to the impact of HRIS in the Municipality was determined using Cronbach's Coefficient Alpha (Alpha = 0.918). This alpha coefficient indicates a very high level of internal consistency of the items and hence, a high degree of reliability. The reliabilities for the individual dimensions were also assessed and ranged from 0.697 (impact of HRIS on HR functions), to 0.705 (impact of HRIS on organizational efficiency), to 0.804 (impact of HRIS on cost management), to 0.828 (impact of HRIS on time management) to 0.845 (managerial satisfaction with the HRIS).

Administration of the measuring instrument: The questionnaire was sent to all respondents via email. Respondents then clicked on the link provided in the email to complete the questionnaire. The survey tool used is Survey Monkey.

Statistical analysis: Descriptive (means, standard deviations) and inferential (ANOVA, t-test, Post Hoc Scheffe's test) statistics were used to analyze the quantitative data. The data was captured using Excel (Version 5), processed with SPSS and presented using tabular and graphical representations.

\section{Results}

The perceptions of line managers were assessed by asking them to respond to various aspects of the HRIS (Human Resource Information System) using a 1 to 5 Likert scale. The results were processed using descriptive statistics (Table 2).

Table 2: Descriptive Statistics: Key Dimensions of HRIS

\begin{tabular}{|c|c|c|c|c|c|c|c|}
\hline Dimension & Mean & $\begin{array}{l}95 \% \\
\text { Interval } \\
\text { Lower } \\
\text { Bound }\end{array}$ & $\begin{array}{l}\text { Confidence } \\
\text { Upper } \\
\text { Bound }\end{array}$ & Variance & $\begin{array}{l}\text { Std. } \\
\text { Dev. }\end{array}$ & Min. & Max. \\
\hline Impact of HRIS on HR functions & 3.501 & 3.390 & 3.612 & 0.316 & 0.5626 & 2.0 & 5.0 \\
\hline Impact of HRIS on time management & 3.543 & 3.401 & 3.684 & 0.512 & 0.7157 & 1.4 & 5.0 \\
\hline Impact of HRIS on cost management & 3.313 & 3.168 & 3.458 & 0.540 & 0.7351 & 1.2 & 5.0 \\
\hline Managerial satisfaction with the HRIS & 3.441 & 3.305 & 3.576 & 0.470 & 0.6852 & 0 & 5.0 \\
\hline $\begin{array}{l}\text { Impact of HRIS on organizational } \\
\text { efficiency }\end{array}$ & 3.263 & 3.122 & 3.122 & 0.510 & 0.7144 & 0 & 5.0 \\
\hline
\end{tabular}


From Table 2 it is evident that the respondents have varying views of the HRIS, which in descending level of mean score value is:

- Impact of HRIS on time management (Mean $=3.543)$

- Impact of HRIS on HR functions (Mean = 3.501)

- Managerial Satisfaction with the HRIS (Mean = 3.441)

- Impact of HRIS on cost management (Mean = 3.313)

- Impact of HRIS on organizational efficiency (Mean = 3.263)

Whilst respondents have the most positive view of the impact of HRIS on the time management component and are least convinced of the potential of HRIS to bring about organizational efficiency in the organization, when compared to a maximum attainable score of 5 it is evident that improvement is needed in each of the aspects of the HRIS. In order to assess where these improvements lie, frequency analyses were conducted. In terms of the impact of the HRIS on time management, it was found that $48.5 \%$ of respondents agreed and a further $14.9 \%$ strongly agreed that the new HRIS system has contributed positively to time management via the employee self service module. An almost equal amount of respondents disagreed and strongly disagreed $(13.9 \%$ and $14.9 \%$ respectively) that HRIS has reduced the time spent on processing paperwork and that the HRIS enabled them to carry out HR tasks quicker. A significant percentage of respondents were uncertain regarding the decreased time spent on making staff decisions since more employee information is generated $(30.7 \%)$ and that the HRIS has decreased time spent on inputting data allowing staff to focus on more strategic tasks (28.7\%). In terms of respondents' perceptions regarding the impact of the HRIS on HR functions, it was found that $45.5 \%$ of respondents agreed and a further $16.8 \%$ strongly agreed that the HRIS has improved the data input process by eliminating a manual need to capture data as monthly updates are done and stored on the system. However, $13.9 \%$ of the respondents disagreed that the performance management module has contributed significantly to the overall performance management processes and the information generated from the HRIS helps to make more effective promotion decisions by viewing employees' performance outcomes and ratings. Lastly, $56.4 \%$ of respondents were uncertain whether the managing and record keeping of industrial relations is made more efficient as a result of the HRIS.

In terms of managerial satisfaction derived from the HRIS, it was found that $48.5 \%$ agreed and a further $18.8 \%$ strongly agreed that HRIS could be better utilised in that at the current moment it is not being used to its full capabilities and has not reached its full potential. On the contrary, $21.8 \%$ of respondents disagreed that communication between employees and HR has been more efficient and timely as a result of having the HRIS. A significant amount of respondents (44.6\%) were uncertain whether the executive leave approval has made the leave processes much easier, online and automated. In terms of the impact of HRIS on cost management, a significant amount of respondents (54.4\%) agreed that the cost impact the HRIS has had on pay processing is substantial and, therefore, a definite value add. However, it was also found that $19.8 \%$ of the managers disagreed and a further $5.9 \%$ strongly disagreed that the HRIS has led HR to become a paperless environment thus saving on costs. Almost an equal percentage of respondents were uncertain that the HRIS has decreased the overall HR expenses by saving on a number of costs otherwise incurred by not having an integrated online HRIS (37.6\%) and that the HRIS has decreased training expenses as it has been an easily understood system (35.6\%). In terms of the respondents' perceptions of the impact of the HRIS on organization efficiency, a significant percentage of managers $(62.4 \%)$ agreed and a further $7.9 \%$ strongly agreed that the HRIS has aided the Municipality to attain the overall HR strategy. However, it was also found that $39.6 \%$ of the managers disagreed and a further $5.9 \%$ strongly disagreed that the HRIS has delivered their system as promised and does not need major modifications. Lastly, it was found that $35.6 \%$ of the managers were uncertain that the HRIS has given the Municipality an added advantage to manage staff when compared to other municipalities. The influence of the biographical variables (age, gender, race, educational category, length of service and cluster) on managerial perceptions of the efficiency of the HRIS was evaluated using tests of difference ( $t$ test and ANOVA).

Hypotheses 1: There is a significant difference in the perception of managers varying in biographical profiles (age, gender, race, educational category, length of service and cluster) regarding the impact of HRIS (on HR functions, cost management, time management, managerial satisfaction and organization efficiency) respectively (Table 3 to Table 5 ). 
Table 3: t-Test, Dimensions of HRIS and Gender

\begin{tabular}{|c|c|c|c|c|c|c|c|c|c|}
\hline \multirow[t]{3}{*}{ Dimension of HRIS } & \multicolumn{6}{|c|}{ Gender } & \multirow[t]{3}{*}{$\mathbf{T}$} & \multirow[t]{3}{*}{ Df } & \multirow[t]{3}{*}{$\mathbf{p}$} \\
\hline & \multicolumn{3}{|c|}{ Male } & \multicolumn{3}{|c|}{ Female } & & & \\
\hline & $\mathbf{N}$ & Mean & SD & $\mathbf{N}$ & Mean & SD & & & \\
\hline Impact of HRIS on HR Functions & 42 & 3.452 & 0.6058 & 59 & 3.536 & 0.5323 & -0.731 & 99 & 0.467 \\
\hline $\begin{array}{l}\text { Impact of HRIS on time } \\
\text { management }\end{array}$ & 42 & 3.457 & 0.7513 & 59 & 3.603 & 0.6893 & -1.012 & 99 & 0.314 \\
\hline $\begin{array}{l}\text { Impact of HRIS on cost } \\
\text { management }\end{array}$ & 42 & 3.214 & 0.7018 & 59 & 3.383 & 0.7559 & -1.139 & 99 & 0.257 \\
\hline $\begin{array}{l}\text { Managerial satisfaction with the } \\
\text { HRIS }\end{array}$ & 42 & 3.396 & 0.7320 & 59 & 3.472 & 0.6545 & -0.552 & 99 & 0.582 \\
\hline $\begin{array}{l}\text { Impact of } \quad \text { HRIS } \\
\text { organizational efficiency }\end{array}$ & 42 & 3.186 & 0.7579 & 59 & 3.319 & 0.6829 & -0.921 & 99 & 0.359 \\
\hline
\end{tabular}

Table 3 indicates that there is no significant difference in the perceptions of male and female managers regarding the impact of the HRIS (on HR functions, cost management, time management, managerial satisfaction and organization efficiency) respectively. Hence, hypothesis 1 may be rejected in terms of gender.

Table 4: ANOVA, Dimensions of HRIS and Biographical Variables

\begin{tabular}{|c|c|c|c|c|c|c|c|c|c|}
\hline \multirow{2}{*}{\multicolumn{2}{|c|}{ Dimensions of HRIS }} & \multicolumn{2}{|l|}{ Age } & \multicolumn{2}{|c|}{ Tenure } & \multicolumn{2}{|l|}{ Race } & \multicolumn{2}{|c|}{$\begin{array}{l}\text { Cluster/ } \\
\text { Department }\end{array}$} \\
\hline & & $\mathbf{F}$ & $\mathbf{p}$ & $\mathbf{F}$ & $\mathbf{p}$ & $\mathbf{F}$ & $\mathbf{p}$ & $\mathbf{F}$ & $\mathbf{p}$ \\
\hline Impact of HRIS on HR Fun & tions & 1.826 & 0.148 & 0.772 & 0.513 & 0.337 & 0.799 & 0.820 & 0.573 \\
\hline $\begin{array}{l}\text { Impact of HRIS on } \\
\text { management }\end{array}$ & time & 0.611 & 0.609 & 0.912 & 0.438 & 1.400 & 0.248 & 0.718 & 0.657 \\
\hline $\begin{array}{l}\text { Impact of HRIS on } \\
\text { management }\end{array}$ & cost & 0.202 & 0.895 & 0.066 & 0.978 & 0.906 & 0.441 & 2.546 & $0.019 *$ \\
\hline $\begin{array}{l}\text { Managerial Satisfaction } \\
\text { HRIS }\end{array}$ & with & 0.533 & 0.661 & 0.731 & 0.536 & 1.979 & 0.122 & 0.871 & 0.532 \\
\hline $\begin{array}{l}\text { Impact of } \quad \text { HRIS } \\
\text { organizational efficiency }\end{array}$ & on & 1.117 & 0.346 & 1.370 & 0.256 & 1.049 & 0.374 & 0.796 & 0.592 \\
\hline
\end{tabular}

From Table 4 it is evident that there is no significant difference in the perception of managers varying in biographical profiles (age, tenure, race) regarding the impact of the HRIS (on HR functions, cost management, time management, managerial satisfaction and organization efficiency) respectively. Hence, hypothesis 1 may be rejected in terms of age, tenure and race. However, from Table 4 it is evident that there is a significant difference in perception of managers from the different clusters regarding the impact of the HRIS on cost management at the $5 \%$ level of significance. However, Table 4 also indicates that there is no significant difference in the perceptions of managers varying in clusters regarding the impact of the HRIS on the remaining dimensions of the HRIS (on HR functions, time management, managerial satisfaction and organization efficiency) respectively. Hence, hypothesis 1 may only be accepted in terms of clusters and cost management at the $5 \%$ level of significance. In order to assess where the significance lies in terms of clusters and cost management, mean analyses where undertaken (Table 5).

Table 5: Mean Analyses: Perceptions of managers from various clusters regarding Cost Management

\begin{tabular}{llllll}
\hline Cluster & N & Mean & Std. Deviation & F & p \\
\hline Office of the City Manager & 2 & 4.400 & 0.8485 & & \\
Finance & 7 & 2.943 & 0.8059 & & \\
Programme Management & 5 & 3.280 & 0.6099 & \\
Corporate and Human Resources & 65 & 3.391 & 0.7495 & \\
Governance & 4 & 3.450 & 0.5508 & & \\
Human Settlements and Infrastructure & 8 & 2.550 & 0.4504 & & \\
Community and Emergency Services & 2 & 3.200 & 0.0000 & & \\
Economic development and Planning & 8 & 3.475 & 0.3694 & 2.546 & $0.019^{*}$ \\
Total & 101 & 3.313 & 0.7351 & & \\
\hline
\end{tabular}

$* \mathrm{p}<0.05$ 
From Table 5 it is evident that the managers in the various clusters differ significantly in terms of their views of the impact of the HRIS on cost management. The office of the City Manger (Mean $=4.400$ ) followed by Economic Development and Planning (Mean $=3.475$ ) and closely followed by Governance (Mean $=3.450$ ) have the most positive view of the impact of HRIS on cost management. However, the managers in the clusters of Human Settlements and Infrastructure $($ Mean $=2.550)$ and Finance (Mean $=$ 2.943 ) are not convinced that HRIS is having a positive impact on cost management.

Discussion of Results: In this study the extent to which the new HRIS has impacted on organizational efficiency was evaluated through measuring the impact of the system on specific key variables (time management, cost management, managerial satisfaction, and HR functions). Organizational efficiency encapsulates how well a company uses money and, in simple terms, can be measured by return on investment (Gish, 2012).

Impact on HR functions: The effectiveness of HRIS in achieving organizational efficiency has a positive effect on the impact on HR Functions (Mean = 3.501). Targowski and Deshpande (2001) suggested that part of the utility of a HRIS is its positive impact on traditional HR processes such as recruitment, selection as well as training and development. Therefore, one can examine a positive contribution in these traditional HR functions as a result of having a successfully implemented HRIS. According to Pasqualetto (1993, p. 94), “...the number of functions and management objectives supported by the HRIS of the future is growing, requiring not only data and processes specific to the function, such as applications, but also data that are companywide, such as the job descriptions, career planning, performance appraisal, management development, training and succession planning". This suggests that HRIS is not only playing a vital role in various HR functions now but will continue to contribute to adding value to the various functions in the future. Similarly, Kovach and Cathcart (1999, p. 275) agree with Pasqualetto (1993) that "HRIS can support long range planning, with information for labour force planning, and supply and demand forecasts; staffing with information on equal employment, separations, and applicant qualifications; and development with information on training program costs and trainee work performance". HRIS can also support compensation programs with information on pay increases, salary forecasts, and pay budgets and, labour/employee relations with information on contract negotiations and employee assistance needs.

Targowski and Deshpande (2001) agree that HRIS positively contributes to the various HR functions. The following functions are citied as having the most benefit: recruitment and selection; personnel administration; time, labour, and knowledge management; training and development; pension administration; compensation and benefit administration; payroll; performance; labour relations; expense and travel administration; organizational management and health and safety. Likewise, Lori and Elaine (2002) agree that HRIS offers simplification in processes such as performance appraisals as software tracks core competencies and provides the manager with tips for coaching. Training and development has also been improved as a result of HRIS as training, tracking of skills and competencies are now possible. The HR department holds the responsibility for ensuring, measuring, and maintaining the quality of human capital in the organization. Effective performance management plays a critical role in the successful implementation of organizational strategy and gaining a competitive advantage (Shani \& Tesone, 2010). An effective performance appraisal calls for a comprehensive system that will integrate the relevant functions in evaluating and tracking employee performance. However, studies reveal that little effect of HRIS on the process of performance management among HR executives, who still rely on paper and pencil administration and hard copy documentation of employee evaluation (Shani \& Tesone, 2010). "The use of HRIS has significant impact on the current affairs between the management and the employees, as well as the characteristics and the environments of the contemporary workplace" (Shana \& Tesone, 2010, p. 43). This is due to managers and employees having access to relevant information such as company rules, policies, and regulations. Similarly, Hill, Jerram and Troshani (2010) state that HRIS can keep track of information concerning applicant/employee qualifications and demographics, recruitment, professional development, performance evaluation, payroll, retention and attrition.

Impact of HRIS on time management: Managers in eThekwini Municipality perceived the impact of time management in relation to the HRIS in a positive manner (Mean =3.54). According to Blau (2012), HRIS makes HR easier by streamlining administrative processes and allowing the HR department more time to spend on higher value and strategic work. Pandya (2013) agrees with Blau (2012) that a company will require fewer employees to perform administrative tasks such as record keeping and, HR managers would have more available time to check and analyze strategic decisions. HR information systems will 
reduce the total time employees spend on routine administration tasks (Daniel, 2010). Greater focus can be paid to other duties that are more strategic and dynamic than administration tasks. Johnson and Gueutal (2012) are also of the view that workflow technology can reduce the cycle time of processes and streamline decision making. By automating and devolving many routine HR tasks to line management, HRIS provides HR professionals the time needed to direct their attention towards more critical business and strategic level tasks such as leadership development and talent management (Dery et al., 2009).

However, in the study conducted by Beadles et al. (2005), it was also found that perceptions of the effects of a HRIS on time savings are mixed. The HR functions of recruitment, training, selection were not positively effected as results indicated that there were little time savings in these areas. However, Beadles et al. (2005) goes on to explain that certain institutions did in fact realize some saving on other administrative tasks such as processing paperwork, correcting errors and inputting data. A clear distinction was drawn between time saving on the various HR functions and administrative tasks. One can examine a clear time saving on the latter of the two variables that were examined. Bal et al. (2012) disagrees with Beadles et al. (2005) and believes that the use of web technology to deliver HR will leave the specialist with more time to perform strategic activities. Likewise, Shani and Tesone (2010) state that by improving efficiency and effectiveness of the HR day-to-day administrative tasks, HRIS allows HR staff to dedicate more time to strategic decision making and planning which provides more value to the organization to enhance its position within it. Whilst HR tasks become more complex in conjunction with organizational trends such as globalisation, HR professionals rely heavily on HRIS to fulfil their job functions. HRIS provides powerful computing capabilities, thereby improving procedures and processes that were carried out less efficiently before, such as regulatory reporting and compliance.

Impact of HRIS on cost management: The effectiveness of cost management on achieving organizational efficiency was also positively perceived (Mean $=3.31$ ). Pandya (2013) maintains that numerous authors have proposed that the use of HRIS would reduce HR costs by automating information and reducing the unnecessary requests of HR employees that can be addressed through self help. Beadles et al. (2005) share a similar view in that HRIS creates informational efficiencies and cost savings that enable HR departments to turn their attention to providing better analyses of current data and creative uses of the HRIS, thereby contributing to strategic decisions. HRIS automate and devolve routine administrative and compliance functions traditionally performed by corporate HR departments and can facilitate the outsourcing of HR. In doing so, HRIS not only makes it possible for organizations to significantly reduce the costs associated with HR delivery but also to reassess the need for retaining internal HR capabilities (Dery et al., 2009). Lippert and Swiercz (2005) agree with Beadles et al. (2005) and state that HRIS implementation success has emerged as a significant challenge for organizations attempting to justify planned investments or recover expenses linked to investments already incurred. Kovach and Cathcart (1999) believe that the value of the information derived from a HRIS must be weighed against the cost of generating the information to determine whether the information represents a good investment. A HRIS is also an investment to an organization including the various other costs such as hardware, training and maintenance costs. However, it is also noted that the largest impediments to reaching the full potential of a HRIS are lack of money or the costing factor.

A study investigating the reasons for introducing a HRIS revealed that $79 \%$ of 33 firms recognised cost savings as the main driving force (Sergio, Pez, Sebasti \& Ugarte, 2010). In a similar study conducted by Lori and Elaine (2002) it was found that a good e-recruiting model in a HRIS can reduce the hiring time by two-thirds and lower costs by $90 \%$. There has been far greater emphasis placed on useful measures for assessing the overall benefits of the HRIS investments (Shibly, 2011). However, there is no accepted or overall framework that can be used to assess the success of a HRIS. Shibly (2011) elaborates that the cost of a HRIS system is extensive and therefore, it is important that the benefits derived from the implementation should be assessed. If the system can provide the organization with a competitive advantage by improving the HR decision making process, this would have enormous implications on productivity, cost reductions and product quality. Shani and Tesone (2010) note that although a HRIS can provide both administrative and strategic advantages, they are expensive systems to purchase and implement. The initial costs of developing a HRIS are high while the implementation process can last between three to nine months and usually requires the organization to remain with the system for at least eight years. However, Shani and Tesone (2010) state that tailored-HRIS can improve HR staff leverage and help achieve ROI (return on investment) in a few years. It is also warned that while the costs are usually unknown, it is more difficult to quantify all the intangible benefits derived from HRIS. In order to 
reduce the costs of HRIS, an organization can purchase off-the-shelf applications composed of HR database programmes, aimed at meeting the general needs of the HR function.

Impact of HRIS on organizational efficiency: In this study, perceptions of the effectiveness of the HRIS in bringing about organizational efficiency was relatively positive (Mean $=3.26)$. Beadles et al. $(2005$, $\mathrm{p}$. 40) disagree that HRIS can bring about organizational efficiency and state "A significant problem with deciding whether HRIS benefits the organization is that of measuring the effect of HR and more particularly HRIS on the bottom line. There are few cut ways to measure the overall value of HRIS. While there are measurements for administrative HRIS such as cost reductions in HR departments, it is difficult to measure precisely the return on investments and specific improvements in productivity within the HR department". However, one particular study suggests that there is evidence that HRIS can improve shareholder value (Brown, 2002). Recent research also shows that organizations that successfully adopt sophisticated HR technology tools outperform those that do not (Johnson \& Gueutal, 2011). Johnson and Gueutal (2012) agree with Beadles et al. (2005) and state that the delivery, support and management of HR depend on technology and in the HRIS. Research reflects that implementing HRIS can enhance an organization's long-term productivity and profitability. The HRIS is not only increasing efficiency but is also transforming the HR function (Johnson \& Gueutal, 2012). If a HRIS is used effectively, it can definitely make the HR function more efficient, better informed and better able to accurately communicate how it adds value to an organization. Beadles et al. (2005) also state that administrative HR is much more efficient when combined with IT as HR managers are better able to handle and analyze large amounts of data. However, strategic HRIS is more difficult to measure because there is no way to be sure that the benefits are a direct result of the strategic deployment of the HRIS.

Brown (2013) attributes the efficiency of HRIS to the system's ability to produce more effectively and faster outcomes than done on paper. However, Brown (2013, p. 1) also cautions that "Implementing an HRIS program may seem a necessary step for a company, but unless it will be an effective tool for HR operations, it will not help increase efficiency and may hinder it instead". Pasqualetto (1993) states that a new era is at hand as the HR function and its system support have become strategic partners in managing change within an organization. The re-engineering or work process improvement that has emerged as a key function of HRIS development today would not have been possible without some of the technological advances of recent years. Kovach and Cathcart (1999) explain that the benefits derived from the information are obvious as the organization would not be allowed to continue business if it did not use the information to complete required reports or payments. HRIS emphasize doing administrative tasks faster, with less paper or fewer people as many organizations are finding that the most fundamental value of technology is its ability to encourage new thinking that removes the need for layers of administration. "...The most important elements of an HRIS are not the computers, but the information. The focus of any comprehensive HRIS should be on information validity, reliability and utility first and on automation of the process second" (Kovach \& Cathcath, 1999, p. 281). Targowski and Deshpande (2001) make reference to a study conducted that suggested that companies that use technology effectively to manage the HR function will have a tremendous advantage over those that do not. It is also noted that better knowledge management leads to a firm's better competitive advantage in the marketplace and better stakeholders' satisfaction. In a study conducted by Ngai and Wat (2006) it was found that 60 percent of Fortune 500 companies use a HIRS to support daily HR operations. HRIS is not only used for administrative purposes but also for strategic and business decision making purposes.

Managerial satisfaction with the HRIS: In this study, the effectiveness of the HRIS in achieving organizational effectiveness brought about managerial satisfaction (Mean $=3.44$ ). Panday (2013), however, believes that managers are not always satisfied with the HRIS and finds that directors are generally satisfied but do not see many benefits from its usage outside of its effect on information and information sharing. Johnson and Guental (2011) are of the view that the HRIS is accompanied by greater expectations from employees for more data and more accessibility and this could impact on managerial satisfaction with the system. Managerial satisfaction with an HRIS may also be affected by the distance and isolation that it can create between HR and employees. Managers are often used to working with HR professionals on a face-to-face basis and may find it difficult to use an online system to seek answers to their questions to complete tasks. Undoubtedly, the HRIS enables more HR content to be made available online and other administrative tasks are assigned to employees to manage; hence, the need for HR staff is substantially reduced. This weakens the relationship between HR managers and the organization and could potentially lead to HR staff feeling dissatisfied due to the relationship breakdown (Johnson \& Geuntal, 2012; Sergio et al., 2010). 
Johnson and Guental (2012) emphasizes that a new HR system involves new skills and roles for HR staff. In larger organizations HR staff tends to focus more on complex HR policy decisions and exceptions which may have financial implications for the organization. The HRIS works well with routine administrative tasks but cannot perform complex or sensitive employee issues. Hence, the level of education and experience required for success in a HR career will increase over the years and the profession will increasingly be divided into two groups. The first is the content experts who work with the HRIS and provide a company specific knowledge base for the system and the second is a HR generalist, who focuses on organizational effectiveness. This future of the HR professionals could result in managers being dissatisfied with the use of the HRIS due to the ambiguity and the changing nature of the profession and role including the higher education and experience needed for a career in this field (Johnson \& Guental, 2012; Kavanagh \& Thite, 2009). Furthermore, Shani and Tesone (2010) note that a potential factor that could hamper HR managers' satisfaction with the HRIS is who is in charge of the system which affects both implementation and management. The development of the HRIS requires input from IT and HR departments and it is not uncommon for disputes over areas of responsibility to arise, though many believe that the control of the entire HRIS should reside with HR. On the positive side, researchers do maintain that a great deal of software programs are helping HR managers to be more effective and more are still to come (Kovach \& Cathcart, 1999; Sergio, 2010; Shani \& Tesone, 2010). Many experts forecast that the PC (including HRIS) will become the centre tool for all HR managers.

Impact of Biographical variables of the perceptions the influence of new HRIS system on Organizational Efficiency: Whilst none of the biographical variables (gender, age, educational level, length of service, race) had a significant impact on organizational efficiency it is evident that the managers in the various clusters differ significantly in terms of their views of the HRIS and cost management. The office of the City Manager $($ Mean $=4.400)$ followed by Economic Development and Planning (Mean $=3.475)$ and closely followed by Governance (Mean $=3.450)$ have the most positive view of the impact of HRIS on cost management. However, the managers in the clusters of Human Settlements and Infrastructure (Mean $=2.550$ ) and Finance $($ Mean $=2.943$ ) are not convinced that HRIS is having a positive impact on cost management. Similarly, in a study conducted by Bal et al. (2012) it was found that there was no significant correlation between the perceived satisfaction of HRIS and the biographical variables (gender, education and age) respectively. However, Bal et al. (2012) found that there exists a significant difference in the perceptions of managers varying in managerial position regarding HRIS within the organization.

\section{Conclusion and Recommendations}

The implementation of the HRIS in the Municipality, like the debut of any new system in an organisation, is accompanied by positive and negative perceptions. It is, therefore, recommended that an internal audit should always be conducted after the introduction of a new system to determine how best the system can be modified to deliver the original system as promised to meet employees' expectations. The Municipality can conduct an annual internal audit at the end of each year through a compulsory online survey. Employee feedback could reveal important factors that could improve the system and its usage and, enable the vendor to deliver the desired product. This will ensure that the employees' expectations of a streamlined and fully integrated, online, shared HRIS is achieved. Respondents also reflected mixed perceptions of the effectiveness of the HRIS in bringing about more effective communication between employees and HR as well as increased coordination between HR and various business stakeholders in the Municipality. It is recommended that the Municipality initiates automatic notifications to be embedded in the system to notify HR of employee requests so as to make responses almost immediate. Furthermore, the Municipality can institute a call centre and help desk or online assistance to ensure that timely assistance is provided to employees, thereby facilitating the communication between employees and HR. In addition, Municipality can hold train-the-trainer sessions and identify super users in each division to assist in training colleagues in their divisions or offering assistance as and when it is needed. This will also reduce the amount of money spent on training whilst trying to up skill employees on the system.

The modules on the HRIS system should be aligned to the Municipality's overall functioning in order to gain congruence. For example, the HRIS should encapsulate all the steps in the hiring process. Also, the performance management module should be congruent with the Municipality's overall performance management process in order to effectively manage performance in the entire Municipality. It is also important to nurture the organizational culture needed to support the new HRIS in the Municipality, like 
in any other organization. For example, the organizational culture needs to skilfully be transformed from a paper-based to an online environment with more online information that facilitates decision making. The system should cater for all business processes and tasks in order to reduce paperwork and enhance the spontaneity and quality of decision and, should be accompanied by a fast bandwidth. It is also recommended that the HRIS be implemented and managed in a manner that facilitates the attainment of the overall HR strategy. New targets should be set for the HRIS to achieve, thereby improving its effectiveness in promoting the ultimate HR strategy. The manner in which data is captured, stored and controlled is imperative in achieving this goal. A well managed HRIS enables readily available information to be translated into more information sharing and enhanced knowledge transfer and management due to information storage, acquisition and accessibility. It has the potential to enhance the speed and quality of decision making and the HR strategy, thereby enhancing organizational effectiveness.

Recommendations for Future Research: In this study, it was noted that the HRIS is still currently being used to conduct more administrative tasks. Furthermore, managers noted that the HRIS could be better utilised in that it is currently not being used to its full capabilities and has not reached its full potential. This may partially be due to the fact that the DynamiQue Resourcelink (DRL) HRIS is still new in the Municipality. It is therefore, imperative to conduct future research in order to assess whether the system has become a fully-fledged, well implemented and integrated system that aligns HR practices to the Municipality's HR strategy and enables the HR Professionals to operate predominantly at the strategic level rather than the administrative level.

\section{References}

Appanna, T. (2008). E-Thek People Project Charter. eThekwini Municipality. Version 1.3 (2008). Organisational Unit: Department of Human Resources, 1-39.

Bal, Y., Bozkurt, S. \& Ertemsir, E. (2012). The Importance of Using Human Resources Information Systems (HRIS) and a Research on Determining the Success of HRIS. Knowledge and Learning: Global Empowerment; Proceedings of the Management, Knowledge and Learning International Conference 2012, International School for Social and Business Studies, Celje, Slovenia, 53-62.

Beadles-II, N. A., Lowery, C. M. \& Johns, K. (2005). The Impact of Human Resource Information Systems: An Exploratory Study in the Public Sector. Journal of Communications of the IIMA, 5(4), 39-46.

Becker, B. E., Huselid, M. A. \& Ulrich, D. (2001). The HR Scorecard: Linking people, strategy and performance. Boston: Harvard Business School Press.

Blau, M. A. (2012). 7 Ways HRIS will save you time and money. [Online]. Accessed from the World Wide Web: http://hrservices.sharedhr.com/blog/bid/227319/7-More-Ways-HRIS-Software-WillSave-You-Time-and-Money.

Brown, S. (2013). Human Resource Information System. [Online]. Accessed on 29 July 2013 from the World Wide Web: http://www.yousaytoo.com/human-resource-information-systemhris/248135.

Brown, S. (2008). Human Resource Information Systems. CompareHRIS.com Accessed on 16 November 2013 from the World Wide Web: http://www.comparehris.com/ Human-Resource-InformationSystems- $/$

Brown, D. (2002). E-HR - Victim of unrealistic expectations. Canadian HR Reporter, 15(16), 1-6.

Carneiro, F. (2011). HRIS and global compliance framework. IHRIM Workforce Solutions Review, October/November, 1-7.

Carrell, M., Elbert, N., Hatfield, R., Grobler, P., Marx, K. \& van de Schyf, S. (1999). Human Resource Management in South Africa. South Africa: Prentice-Hall Inc.

Chauhan, A., Sharma, S. K. \& Tyagi, T. (2011). Role of HRIS in improving modern HR operations. Review of Management, 1(2), 58-70.

Daniel, H. (2010). Benefits of HRIS. [Online]. Accessed from the World Wide Web: http://benefitof.net/benefits-of-hris/. [18 August 2011].

Dery, K., Grant, D. \& Wiblen, S. (2009). Human Resource Information Systems: Replacing or Enhancing HRM. 15th World Congress of the International Industrial Relations Association IIRA 2009. The New World of Work, Organisations and Employment, Sydney, Australia, 27 August 2009.

Dessler, G. (2005). Human Resource Management. 10 th Edition. USA: Prentice Hall.

Dorel, D. \& Bradic-Martinovic, A. (2011). The role of information systems in human resource management. Munich Personal RePEc Archive (MPRA). Paper No. 35286. [Online]. Accessed on 
16 November 2013 from the World Wide Web: http://mpra.ub.uni-muenchen.de/35286. pp. 120.

Dresser \& Associates. (2013). What is Human Resources Information System (HRIS)? HR, Payroll and Talent Management Solutions. Sage HRMS. Accessed on 16 November 2013 from the World Wide Web: http://www.dresserassociates.com/what-is-hris.php

Gish, W. (2012). Organizational Effectiveness Vs. Organizational Efficiency. [Online]. Accessed from the World Wide Web: http://smallbusiness.chron.com/organizational-effectiveness-vsorganizational-efficiency-22413.html

Govender, K., Pillay, Y. \& Silelidis, C. (2010). Human Resources Unit Presents: A new Software Package. [PowerPoint Slides]. Presented at: HR Shared Services Meeting.

Grobler, P., Warnich, S., Carrell, M., Elbert, N. \& Hatflied, R. (2006). Human Resource Management in South Africa. 3rd Edition. London: South-Western.

Hendrikson, A. (2003). Human resource information systems: Backbone technology of contemporary human resources. Journal of Labour Research, 24 (3), 382-387.

Hill, R. S., Jerram, C. \& Troshani, I. (2010). Exploring the public sector adoption of HRIS. Industrial Management and Data, 11(3), 470-488.

Insight Consulting Partners. (2004). Going global with your HRIS. Accessed from the World Wide Web: http://www.insightcp.com/res_17.htm

Insight Consulting Partners. (2012). The impact of implementing an HRIS. Accessed on 16 November 2013 from the World Wide Web: www.insightcp.com/res_09.html

Johnson, R. D. \& Gueutal, H. G. (2011). Transforming HR through technology: The use of eHR and human resource information system in organisations. SHRM Effective Practices Guidelines Series.

Johnson, R. D. \& Gueutal, G. H. (2012). Leveraging HR Technology for Completive Advantage. SHRM Foundation Executive Briefing. [Online]. Accessed from the World Wide Web: http://www.shrm.org/about/foundation/products/Documents/HRIS\%20Exec\%20Briefing\%20 FINAL.pdf. [16 June 2013].

Kavanagh, M. \& Thite, M. (2009). Human Resource Information Systems. United States of America: SAGE Publications Inc.

Khera, S. N. \& Gulati, K. (2012). Human Resource Information System and its impact on Human Resource Planning: A perceptual analysis of Information Technology companies. Journal of Business and Management, 3(6), 6-13.

Kinnie, N. J. \& Arthurs, A. J. (1996). Personnel specialists' advanced use of information technology. Personnel Review, 2(3), 3-19.

Kovach, K. A. \& Cathcart, C. E. (1999). Human Resource Information Systems: Providing Business with Rapid Data Access Exchange and Strategic Advantage. Public Personnel Management, 28(2), 275281.

Kumar, R. (2012). Human Resource Information System: An Innovative Strategy for Human Resource Management. Gian Jyoti E-Journal, 1(2), 1-12. Accessed on 16 November 2013 from the World Wide Web: www.gjimt.com/GianJyotiE-Journal.htm

Kundu, S. C. \& Kadian, R. (2012). Applications of HRIS in Human Resource Management in India: A Study. European Journal of Business and Management, 4(21), 34-41.

Lawler, E. E., Levenson, A. \& Boudreau, J. W. (2004). HR Metrics and Analytics: Use and Impact. Human Resource Planning, 27(4), 27-35.

Lawler, E. E. \& Mohrman, S. A. (2003). HR as a strategic partner: What does it take to make it happen? Human Resource Planning, 26(3), 15-29.

Lengnick-Hall, M. L. \& Moritz, S. (2003). The impact of e-HR on the Human Resource Management Function. Journal of Labor Research, 24(3), 365-379.

Lippert, K. S. \& Swiercz, M. P. (2005). Human Resource Information System (HRIS) and technology trust. Journal of Information Science, 31(5), 340-353.

Lori, B. \& Elaine, D. (2002). Information Systems: The quiet revolution in Human Resource management. The Journal of Computer Information Systems, 42(2), 17-20.

Lucerna, L. L. C. (2013). HR Payroll Solutions. HRIS Software. Accessed on 16 November from the World Wide Web: http://www.hrpayrollsystems.net/

Miller, M. S. (2004). Establishing value for HR Technology. The Conference Board, R-1350-04-RR.

Nawaz, M. N. (2012). To assess the impact of HRIS in facilitating information flow among the select software companies in Bangalore, India. Research Journal of Management Sciences, 1(3), 1-8.

Ngai, E. W. T. \& Wat, F. K. T. (2006). Human resource information systems: A review and empirical analysis. Personnel Review, 35 (3), 297-314. 
NMA Technologies. (2008). What is HR Systems? NMA Technologies: Professional Systems Integrator. Accessed on 16 November 2013 from the World Wide Web: www.nmatec.com/hrwise/what

Pandya, A. (2013). The impact of Human Resource Information System. [Online]. Accessed from the World Wide Web: http://www.empowernetwork.com/ wealthyashish/blog/potential-benefitsof-hris/. [17 June 2013].

Pasqualetto, J. (1993). New Competencies define the HRIS Manager's Future Role. Personnel Journal, 72(1), 91-99.

Sadiq, U., Khan, A. F., Ikhlaq, K. \& Mujtaba, B. G. (2012). The impact of Information Systems on the Performance of Human Resources Department. Journal of Business Studies Quarterly, 3(4), 77-91.

Sekaran, U. \& Bougie, R. (2010). Research methods for business: A Skill Building Approach. 5th Edition. New York: John Wiley and Sons Ltd.

Sergio, B., Pez, G., Sebasti, M. \& Ugarte, N. (2010). On the quest of choosing an effect HR Information system - assessing its role and key success factors. Horizontes Empresariales, 9(1), 49-54.

Shani, A. \& Tesone, V. D. (2010). Have human resource information systems evolved into internal ecommerce? Emerald Group Publishing Limited, 2(1), 30-48

Sheehan, C., Holland, P. \& De Cieri, H. (2006). Current development in HRM in Australian Organisations. Asia Pacific Journal of Human Resources, 44(2), 132-152.

Shibly, H. (2011). Human resources information systems success assessment: An integrative model, Australian Journal of Basic and Applied Sciences, 5(5), 157-169.

Shiri, S. (2012). Effectiveness of Human Resource Information System on HR Functions of the Organization - A Cross Sectional Study. US-China Education Review, A (9), 830-839.

Targowski, S. A. \& Deshpanade, P. S. (2001). The Utility and Selection of an HRIS. Advances in Completive Research, 9(1), 42-56.

Teo, T. S. H., Soon, L. G. \& Fedric, S. A. (2001). Adoption and impact of Human Resource Information Systems (HRIS). Research and Practice in Human Resource Management, 9(1), 101-117.

Wei, S. \& Feng, A. (2013). Research on applications of Human Resource Information System in SMEs. $2^{\text {nd }}$ International Conference on Science and Social Research (ICSSR) 2013. Atlantis Press, 804-807. 